\title{
Impact of informal physics programs on female university students
}

\author{
Jessica Randolph, Emily Hay, Callie Rethman, and Tatiana Erukhimova \\ Department of Physics \& Astronomy, Texas A\&M University, College Station, Texas 77843 \\ Jonan Phillip Donaldson \\ Center for Teaching Excellence, Texas A\&M University, College Station, Texas, 77843 \\ Jonathan Perry \\ Department of Physics, University of Texas at Austin, Austin, Texas, 78712
}

\begin{abstract}
Informal physics programs can play a vital role in supporting student learning and sense of community beyond the formal settings of a classroom or laboratory. This work builds on a recent study of the impact of facilitating informal physics programs on students' physics identity, sense of belonging, and career skills development by narrowing the focus to specifically examine effects on female students who are underrepresented in physics. We found a statistically significant shift in confidence of choice of major when compared prior to and after facilitating informal physics programs. All female students who were interviewed discussed a positive effect of participating in informal programs on their interest and motivation with regards to the field of physics and the development of characteristics indicative of a growth mindset.
\end{abstract}

2021 PERC Proceedings edited by Bennett, Frank, and Vieyra; Peer-reviewed, doi.org/10.1119/perc.2021.pr.Randolph Published by the American Association of Physics Teachers under a Creative Commons Attribution 4.0 license. Further distribution must maintain the cover page and attribution to the article's authors. 


\section{INTRODUCTION}

Underrepresentation of female students in US physics departments has been a long-term recognized problem [1-3]. Female students often find themselves a minority in their physics classes which aggravates the gender stereotype threat and cultural biases that so many female students experience in their physics careers [4]. The gender stereotype threat can impact female student performance in physics classes $[5,6]$. Lack of sense of belonging in physics can be linked to attrition of female students from the field [7]. Other potentially related factors such as underdeveloped physics self-identity, low self-efficacy, and low motivation can negatively influence female student success and retention [8-16]. A vast majority of prior studies seeking to improve female student representation and retention in physics concentrated on student experiences in formal physics settings such as classrooms and labs while the impact of informal physics programs on student development as a physicist has been often overlooked [17, 18].

Recent publications indicate an increased interest in understanding how student participation in informal physics programs (also called outreach programs) supports the development of a physics identity, enhances retention and persistence, and aids in building a sense of community $[17,19,20]$. In our recent work, we examined the impact of different informal physics programs on a large number of graduate and undergraduate students facilitating these programs [21]. This mixed methods study included five informal physics programs run by the Department of Physics \& Astronomy at Texas A\&M University. The programs differed in scale and frequency spanning from a large annual physics festival with thousands in attendance to year-round smaller-scale events [21]. All of these programs provided the university students with experiential learning, leadership and teamwork, peer mentoring and peer learning, communication skill development, and networking opportunities. Although female students were not a focus of analysis [21], we observed that female students self-reported a positive link between participation in the physics informal programs and their sense of belonging, a parameter that could be crucial for female student retention in the field [7].

In this current study we hone in on the experience of female students facilitating physics informal programs. To our best knowledge, there has been no published data on the impact of informal physics programs on university female students specifically. This paper is the first step to addressing this important question. Using an existing database [21], we examined how such important factors as formation of female student physics identity, mindset, and persistence were influenced by their participation in the informal physics programs. To address issues related to gender stereotype threat and underrepresentation in physics, we believe that it is important to better understand the experiences of female students in the field and how these may be improved on through engagement with informal physics programs.

\section{METHODOLOGY}

To explore the impact of facilitating informal physics programs on female students, we analyzed a subset of data collected from a previous mixed methods study [21]. This prior work collected 117 survey responses and conducted 35 interviews with undergraduate and graduate students who facilitated at least one informal physics program between 20132019 at a large land-grant university. The survey consisted of questions targeting dimensions related to student physics identity as defined below, sense of belonging to the physics community [7], and $21^{\text {st }}$ century career skills [22]. The survey incorporated a subset of items motivated by categories from the Colorado Learning Attitudes about Science Survey [23] and additional items reflecting on the goals of this project [21]. The survey was distributed via email in fall 2019. Interviews were conducted with a volunteer pool of respondents from the survey. Didactic interview questions were developed in collaboration with learning scientists and probed for more in-depth experiences from facilitating informal physics programs.

To analyze interviews, we developed a code book based primarily on the work of Hazari et al. [9] for physics identity. We also incorporated other themes relevant to female students in physics such as gender stereotype threat and persistence in the field $[5,6,10,14]$.

In a previous study [9] physics identity was defined through the dimensions of belief in ability to understand physics content, recognition by self and others as being good at physics, and interest in the field as demonstrated by the desire to understand physics [9]. Additional codes were included by viewing identity through the lens of a Dynamic Systems Model of Role Identity (DSMRI). This model characterizes identity as context-specific self-perceptions, values, goals, emotions, and beliefs [24]. We also defined learning and how learning occurs through the frameworks of Situated Learning Theory and Transformative Learning Theory. These frameworks incorporate assumptions, beliefs, perspectives, and habits of mind [25-27].

Through these lenses we included growth and fixed mindset - that is the demonstration of beliefs that intelligence can grow and change or is immutable [28] - as well as important experiences, accountability, gender stereotype threat, and worldview. A total of 18 codes were used to categorize statements from the interviews. These codes were organized into categories of (i) physics identity (e.g. interest and motivation, recognition, performance and competence, confidence and physics self-efficacy), (ii) persistence (positive or negative), (iii) mindset (growth or fixed), (iv) worldview (cooperative or competitive), (v) important experiences, (vi) accountability (to scientific community, leadership, individual roles), and (vii) gender stereotype threat. Categories i, ii, iv, and vii are grounded in DSMRI, categories ii, vi are grounded in situated learning theory, and categories iii, $\mathrm{v}$ are grounded in transformational learning theory. To code interviews, we split into three teams with each team coding separately, then all 


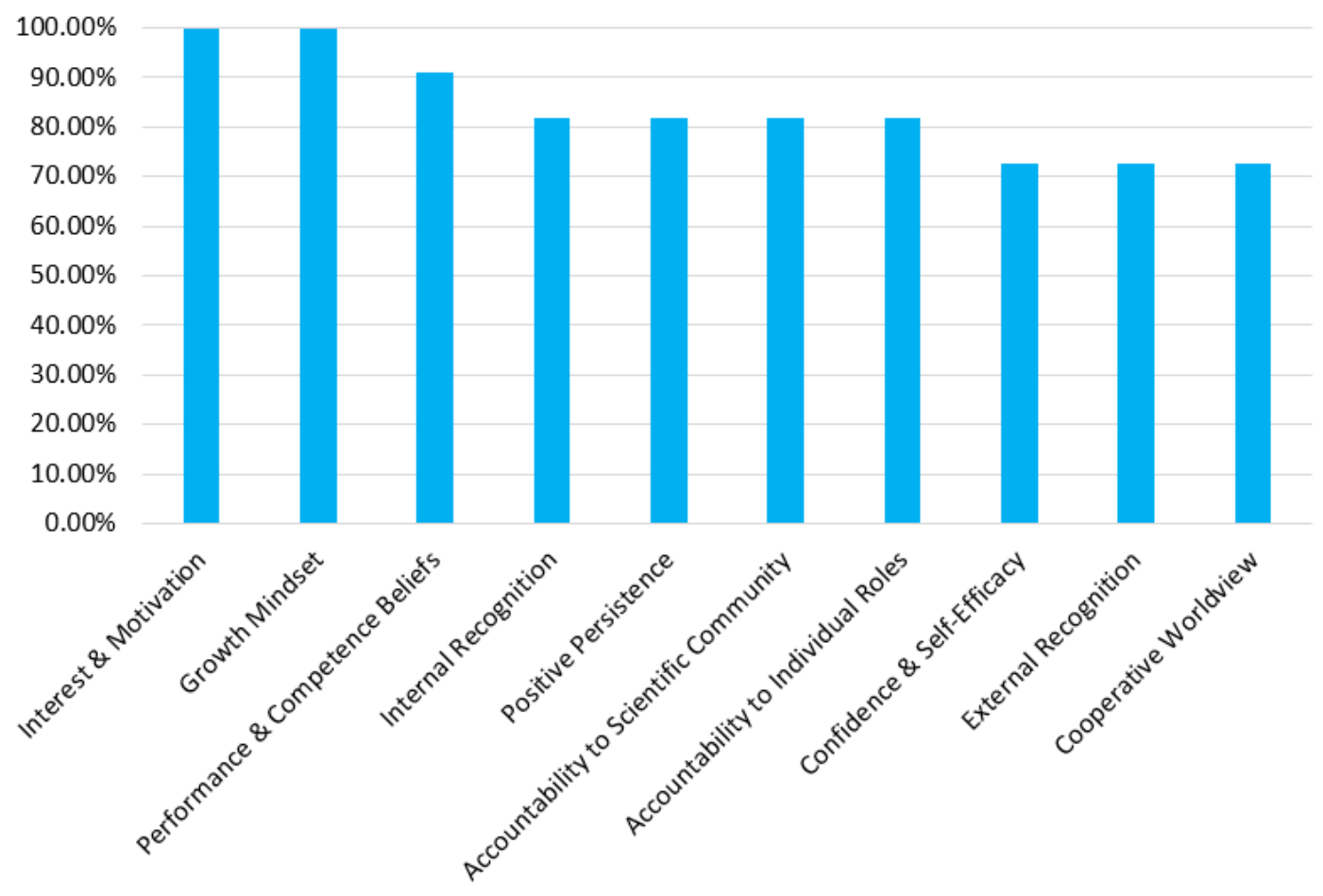

FIG. 1. Frequency with which themes appeared in each interview.

teams met to discuss and resolve differences. After completing this process for all interviews, we achieved an intercoder agreement of $\kappa>0.9$. Each interview was coded by four researchers from this study.

To explore the impacts and connections among the codes used for this study, we looked at both the frequencies of individual codes as well as the relationships between them. To understand the relationships between codes we employed a semantic network map, which provides a visual representation of the significant correlations among multiple ideas, represented as nodes, simultaneously. By creating correlation matrices and determining the centrality of each idea through eigenvector centrality measures, a map is produced where lines between codes indicate statistically significant correlation and colored blocks indicate clusters of codes identified through Girvan-Newman cluster analysis [29]. Larger nodes and a higher number of links correspond to the frequency and centrality of a code $[30,31]$.

\section{RESULTS}

In this section we present results from a survey and interviews which were completed as part of our prior study with a particular focus on the experiences of female students [21]. Our database of 117 completed surveys contained 32 responses from female students, including 20 undergraduate, 11 graduate, and one who was both. Gender was self-reported.
The majority of female respondents were from physics majors, though six were engineering majors and two were from atmospheric and computer science. Interviews were conducted with 35 students, 11 of which were female students. Of the female interviewees, 6 were undergraduate students and 5 were graduate students. During interviews students self-reported on the impacts that their participation in informal physics programs had on their physics identity, values, abilities, and perceptions.

First, we analyzed the results from the survey. Selfreported data showed that male and female students had no statistically significant differences in their perceptions of the impact of informal physics programs on themes such as networking within the department, confidence in communication, and sense of belonging within the field. One theme which showed a statistically significant difference was confidence in choice of major prior to participating in informal physics programs. Using a Mann-Whitney U test [32], we found that female students were less confident at the $p=0.01$ level, with a medium effect size, using Cohen's d with a Hedges' correction, of $d=0.75$. This difference disappeared after participating in informal physics programs, $p=0.49$.

Notable findings from the interviews with female students are shown in Figs. 1 and 2. The frequencies with which themes appeared in interviews, with codes counted once per interview, are shown in Fig. 1. The semantic network map, at the $p<0.05$ level, is shown in Fig. 2. The semantic network map shows growth mindset to be the central theme and is con- 


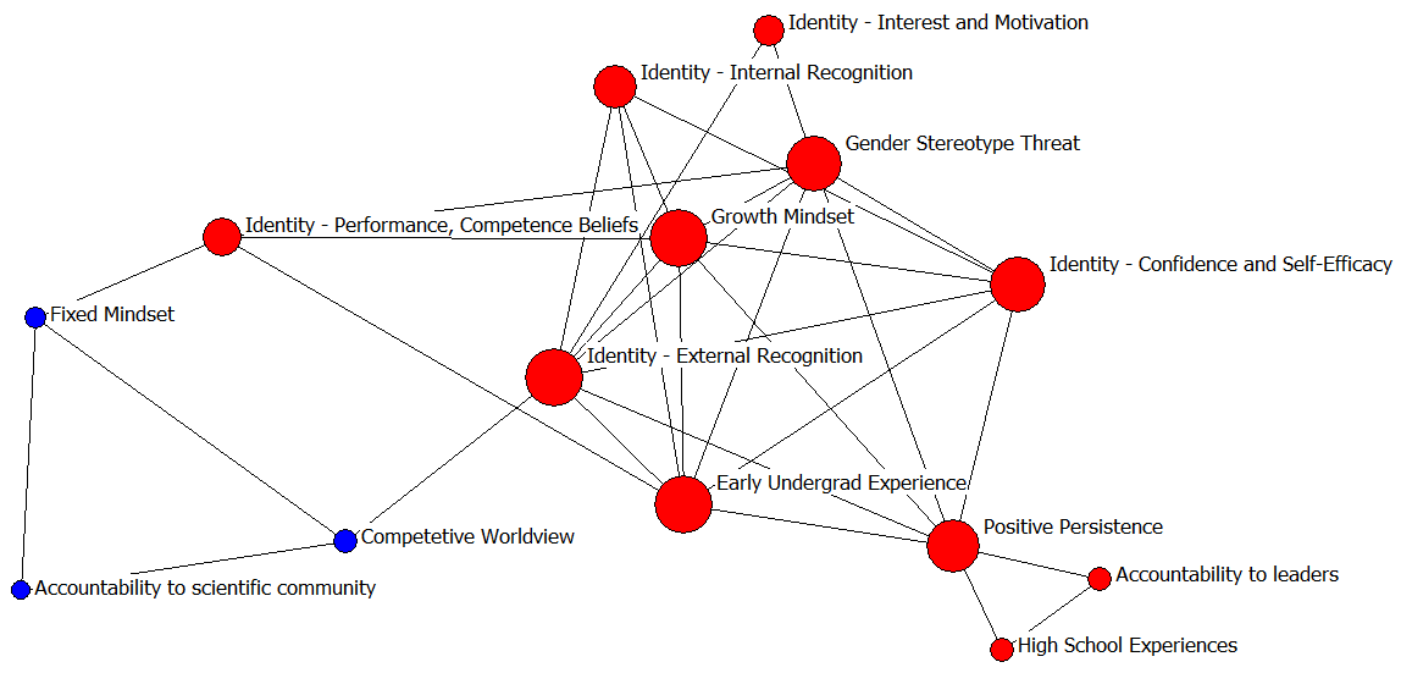

FIG. 2. Network map which shows the relationships between codes for female students. The colors in the figure represent distinct clusters of statistically interconnected ideas but have no other significance.

nected to a majority of other nodes in the map. All students reported characteristics indicative of a growth mindset in regards to challenges they faced or important experiences they had. The involvement in informal physics programs can help students "demystify science" and realize that "anyone can do it", which can then aid in the formation of a growth mindset, or the idea that abilities can be developed through dedication and hard work. We can see this mindset in one student who said, "Anybody can be a physicist; you just have to be willing to put in the work to learn the really hard stuff." Another student expanded on this sentiment by describing their outlook on scientific ability: "I try to see it as this person is good at this aspect of physics but they're not so good at this other aspect of physics. And if I explain it to them, then they'll get better at that aspect... it's just a matter of finding the right words to explain it."

The majority of female students also reported on both internal and external recognition. Students discussed external recognition coming from their peers, faculty, and the general public for their roles in informal physics programs. As one student put it, "[informal physics programs] just make you feel more welcomed into the physics department and into the physics community in general. And you just feel like you have a place that you can belong in. You're contributing something. And I think when you feel like you're contributing something to a community, you feel more a part of it." Recognition from peers, faculty, and knowing that there are other people like them in the field appears to contribute to physics identity development in terms of internal recognition. One student discussed her experience, saying "I will say that I met a lot of friends through physics outreach. And a lot of them were girls in physics. And it was kind of cool to meet a lot of people who were having the same thoughts as me, and we could just kind of band together and have our own little community within the physics department."
The majority of female students reported a positive impact on their confidence and self-efficacy. One student said about her participation in informal physics programs: "it made me cement my understanding of, 'Okay, this is who I am. I am more confident now. This is how I can present myself.", This increase in confidence can potentially lead to a feeling of empowerment. As another student put it: "I've definitely been really reaffirmed that it's something that I want to do and something that I can do, something kind of I'm actually able to do."

Most female students also reported an increase in their performance and competency beliefs. Communicating various physics concepts to the general public and applying their skills to real-world applications through the construction and presentation of physics demonstrations may have helped them develop a "strong grasp of the material" and "solidify some of the learning learned in a classroom [in] the real-world setting." Through their experiences with informal physics programs, these students came to see themselves as more expert in the field. From one student's experience, "[Informal physics programs have] really made me feel like I can be a part of the physics major... I think going out and teaching other people physics made me feel like I knew what I was doing, and made me feel like I could keep going on the route of being a physics major."

All of the female students reported increases in interest and motivation, as participation in informal physics programs allowed the students to gain a deeper appreciation of physics and develop their interests. As one student put it, "You get more involved in more projects, and that only strengthened my love for physics. And not really the academic part of physics, but the actual conceptual part of physics, which is what I like."

Persistence in physics was linked to important early experiences, both in high school and in the first two years of 
undergraduate studies. One student spoke strongly about the influence of her high school physics teacher who gave her a "pull you aside talk" and spoke of her talent in the field, encouraging her to "keep going at it". This event was a significant influence on her choice to pursue physics as a major in college. Another student discussed her fear and uncertainty in her freshman year that physics "wasn't the right major" for her and that she didn't fit "the mold of the physics major." She goes on to say that participating in informal physics programs throughout her early undergraduate helped her to realize that "there's not a specific mold of physics major" and to feel like she could "keep going the route of being a physics major". Persistence was also related to other key ideas such as external recognition, accountability to leadership, and confidence and self-efficacy.

\section{DISCUSSION}

These results suggest that participating in informal physics programs can positively impact female students' physics identity. Many female students who facilitated informal physics programs self-reported increases in both internal and external recognition since these programs can provide students with opportunities to engage with others in the scientific community and the general public. These interactions led to the students feeling recognized externally and reinforced their own identity as a physics person. Students also had the opportunity to dive into various physics concepts as they applied their knowledge and skills to build and present physics demonstrations, which in turn potentially fostered a deeper understanding and appreciation of physics. This could have led to the increase in students' performance and competency beliefs, as well as their interest and motivation. In the framework created by Hazari, recognition, interest and motivation, and performance and competency beliefs are the core pillars for the development of one's physics identity [9]. Prior research shows that a strong physics identity may help women's advancement, persistence, and engagement in physics [9, 10, 14, 33].

Our findings also suggest a connection between recognition and a sense of belonging, as external recognition from peers and faculty, alongside meeting other women in the field of physics and feeling represented within the community, appeared to be related to integration into the physics community for female students. This parallels previous results from
Kalender et al., who reported that recognition from influential people such as professors and teaching assistants correlates to a sense of belonging in the physics classroom for female students [10].

The facilitation of informal physics programs grants students the opportunity to curate their own sense of expertise as they solidify their understanding to communicate ideas and teach physics to others. These experiences, which allow students to continually learn, grow, and challenge themselves as physicists, could assist in the formation of a growth mindset towards intelligence and scientific ability. As noted by Maries and colleagues, this process, in addition to the development of self-efficacy and an increase in sense of belonging, has the potential to fight gender stereotype threat [6].

\section{CONCLUSIONS}

Our mixed method study showed that female students who facilitated informal physics programs experienced a statistically significant shift in their confidence of choice of major when comparing between prior to and after participating in the programs. All female students who were interviewed discussed positive effects of participating in informal programs on their interest and motivation with regards to the field of physics and the development of characteristics indicative of the growth mindset. The majority of female students reported a positive impact on their confidence and self-efficacy, internal and external recognition, persistence, performance, and competency beliefs. While we are encouraged by these results, we must note some limitations present in this study. This study used self-reported data. There was also a selfselection effect as students were volunteers for at least one informal physics program at a large, land-grant university. We hope that our results will stimulate more studies of the effect of informal physics programs on their student facilitators, especially those underrepresented in physics.

\section{ACKNOWLEDGEMENTS}

We want to acknowledge Daniel Choi who conducted some of the interviews. We would also like to thank all students who participated in the survey and interviews. This work was in part supported by the Texas A\&M University College of Science.
[1] N. S. Foundation, Special Report NSF 19-304, National Center for Science and Engineering Statistics, Alexandria, VA (2019), URL https://ncses.nsf.gov/pubs/nsf19304/digest.

[2] L. J. Sax, K. J. Lehman, R. S. Barthelemy, and G. Lim, Phys. Rev. Phys. Educ. Res. 12, 020108 (2016), URL https://link.aps. org/doi/10.1103/PhysRevPhysEducRes.12.020108.
[3] L. McCullough, The Physics Teacher 40, 86 (2002), https://doi.org/10.1119/1.1457312, URL https://doi.org/10. 1119/1.1457312.

[4] J. Blue, A. L. Traxler, and X. Cid, Physics Today 71, 40 (2018).

[5] G. C. Marchand and G. Taasoobshirazi, International Journal of Science Education 35, 3050 (2013). 
[6] A. Maries, N. I. Karim, and C. Singh, Phys. Rev. Phys. Educ. Res. 14, 020119 (2018), URL https://link.aps.org/doi/10.1103/ PhysRevPhysEducRes.14.020119.

[7] K. L. Lewis, J. G. Stout, S. J. Pollock, N. D. Finkelstein, and T. A. Ito, Phys. Rev. Phys. Educ. Res. 12, 020110 (2016), URL https://link.aps.org/doi/10.1103/PhysRevPhysEducRes. 12.020110

[8] V. Sawtelle, E. Brewe, and L. H. Kramer, Journal of Research in Science Teaching 49, 1096 (2012), https://onlinelibrary.wiley.com/doi/pdf/10.1002/tea.21050, URL https://onlinelibrary.wiley.com/doi/abs/10.1002/tea. 21050.

[9] Z. Hazari, G. Sonnert, P. M. Sadler, and M.-C. Shanahan, Journal of Research in Science Teaching 47, 978 (2010), https://onlinelibrary.wiley.com/doi/pdf/10.1002/tea.20363, URL https://onlinelibrary.wiley.com/doi/abs/10.1002/tea. 20363.

[10] Z. Y. Kalender, E. Marshman, C. D. Schunn, T. J. Nokes-Malach, and C. Singh, Phys. Rev. Phys. Educ. Res. 15, 020119 (2019), URL https://link.aps.org/doi/10.1103/ PhysRevPhysEducRes.15.020119.

[11] S. L. Eddy and S. E. Brownell, Phys. Rev. Phys. Educ. Res. 12, 020106 (2016), URL https://link.aps.org/doi/10.1103/ PhysRevPhysEducRes.12.020106.

[12] J. Blue, A. Traxler, and G. Cochran, American Journal of Physics 87, 616 (2019), https://doi.org/10.1119/1.5114628, URL https://doi.org/10.1119/1.5114628.

[13] I. Rodriguez, G. Potvin, and L. H. Kramer, Phys. Rev. Phys. Educ. Res. 12, 020118 (2016), URL https://link.aps.org/doi/ 10.1103/PhysRevPhysEducRes.12.020118.

[14] Z. Hazari, E. Brewe, R. M. Goertzen, and T. Hodapp, The Physics Teacher 55, 96 (2017).

[15] S. Hyater-Adams, C. Fracchiolla, N. Finkelstein, and K. Hinko, Phys. Rev. Phys. Educ. Res. 14, 010132 (2018), URL https: //link.aps.org/doi/10.1103/PhysRevPhysEducRes.14.010132.

[16] T. Perez, J. Cromley, and A. Kaplan, Journal of Educational Psychology pp. 315-329 (2014).

[17] K. Hinko and N. D. Finkelstein, AIP Conference Proceedings 1513, 178 (2012), URL https://aip.scitation.org/doi/abs/ $10.1063 / 1.4789681$.

[18] K. Hinko, J. Seneca, and N. Finkelstein, in Physics Education Research Conference 2014 (Minneapolis, MN, 2014), PER Conference, pp. 115-118.

[19] K. A. Hinko, P. Madigan, E. Miller, and N. D. Finkelstein, Phys. Rev. Phys. Educ. Res. 12, 010111 (2016), URL https:
//link.aps.org/doi/10.1103/PhysRevPhysEducRes.12.010111.

[20] C. Fracchiolla, B. Prefontaine, and K. Hinko, Phys. Rev. Phys. Educ. Res. 16, 020115 (2020), URL https://link.aps.org/doi/10. 1103/PhysRevPhysEducRes.16.020115.

[21] C. Rethman, J. Perry, J. Donaldson, D. Choi, and T. Erukhimova, accepted to Phys. Rev. Phys. Educ. Res. (2021).

[22] P. Heron and L. McNeil, American Physical Society and the American Association of Physics Teachers, Joint Task Force on Undergraduate Physics Programs (2016), URL https://www. compadre.org/JTUPP/docs/J-Tupp_Report.pdf.

[23] W. K. Adams, K. K. Perkins, N. S. Podolefsky, M. Dubson, N. D. Finkelstein, and C. E. Wieman, Phys. Rev. ST Phys. Educ. Res. 2, 010101 (2006), URL https://link.aps.org/doi/10. 1103/PhysRevSTPER.2.010101.

[24] A. Kaplan and J. K. Garner, Developmental Psychology 53, 2036 (2017).

[25] J. Mezirow, An overview on transformative learning (Routledge, Abingdon, 2009), pp. 90-105.

[26] R. Kegan, What "form" transforms? A constructivedevelopmental approach to transformative learning (Routledge, Abingdon, 2009), pp. 35-52.

[27] J. Lave and E. Wenger, Situated learning: Legitimate peripheral participation (Cambridge University Press, New York;Cambridge, U.K;, 1991), ISBN 0521423740;9780521413084;0521413087;9780521423748;.

[28] C. S. Dweck (2014), URL https://www.growthmindsetmaths. $\mathrm{com} /$.

[29] M. Girvan and M. E. J. Newman, Proceedings of the National Academy of Sciences 99, 7821 (2002), URL http://www.pnas. org/content/99/12/7821.abstract.

[30] J. Scott, Social Network Analysis (Sage Publications Ltd, Thousand Oaks, CA, 2017), 4th ed., ISBN 9781473952126 147395212314739521159781473952119.

[31] C. Kadushin, Understanding social networks : theories, concepts, and findings. Charles Kadushin (Oxford University Press, 2012).

[32] L. Cohen, L. Manion, and K. Morrison, Research Methods in Education (Routledge, New York City, New York, 2018).

[33] Z. Y. Kalender, E. Marshman, C. D. Schunn, T. J. Nokes-Malach, and C. Singh, Phys. Rev. Phys. Educ. Res. 16, 010118 (2020), URL https://link.aps.org/doi/10.1103/ PhysRevPhysEducRes.16.010118. 